\title{
Intermediate Students' Arabic Writing Ability: An Exploratory Study in Saudi Arabia
}

\author{
Jihad Al Marazeeq ${ }^{1} \&$ Subhieya Abu Hatab ${ }^{2}$ \\ ${ }^{1}$ Faculty of Education and Arts, Department of Arabic Language, Northern Border University, Saudi Arabia \\ ${ }^{2}$ Department of Education, Northern Border University, Saudi Arabia \\ Correspondence: Jihad Al Marazeeq, Faculty of Education and Arts, Department of Arabic Language, Northern \\ Border University, Saudi Arabia. E-mail: j.baniaamer@yahoo.com
}

Received: December 20, 2020 Accepted: January 21, $2021 \quad$ Online Published: February 3, 2021

doi:10.5539/ijel.v11n2p101 URL: https://doi.org/10.5539/ijel.v11n2p101

\begin{abstract}
This research investigates students' ability in writing skill in the intermediate stage during the academic year 2018/2019. The research followed the analytical descriptive approach in which a test was given to a sample of (300) students in the middle stage in Arar city in Saudi Arabia. The results showed there were no statistically significant differences in students' ability level in writing skills according to gender variable. The results revealed that there were statistically significant differences in the students' ability level in writing skills according to the grade variable in favor of the third-grade average. The researchers recommended the need to increase the Arabic language teachers' awareness of the importance to develop some writing skills such as writing Hamza (a glottal stop) and writing Nunation.
\end{abstract}

Keywords: writing skill, Hamza, Arabic language, intermediate stage

\section{Introduction}

School students in general suffer from weakness in the writing skill. Regarding the importance of the basic stage and the first middle class in particular, students' cognitive abilities are formed, and they are assumed to have established the basic educational skills, including their proficiency in writing skill. It is necessary to determine whether the students in the intermediate stage are able to master writing skill or not, which depends finally on mastering the prior skills to it such as listening and reading skills.

Writing skill is not taught in isolation; it requires proficiency in reading, that provides students with information, knowledge, facts, and experiences that help them express their thoughts, opinions, and feelings. Writing skill is a productive skill as well as the speaking skill, and it is no less important than speaking and reading skills. Arabic language has two basic functions, namely communication and facilitating the process of thinking and expression: writing help fulfill these functions and learn Arabic Language as well (Al-Shanti, 2003).

Writing skill is the most demanding skill since it involves comprehending all other language components as well as it is a good way in which students express their thoughts and feelings that displays essential component of the functional knowledge of reading and writing. As for the functional aspects, it is an important tool for mental health. That is why psychologists have considered it as a means of psychological treatment. The mental and even physical health problems improve and contribute to developing endurance and confronting other psychological problems (Kazdin, 2000).

Writing has a pedagogical value in students' learning process, as it stimulates and develops their mental capabilities, and allows learners to think and reflect, choose structures and words, order thoughts and coordinate style. What makes writing different from other skills is the quality of formulation involved in the writing process. Other relevant skills and capabilities which writing contributes to its artistic value which enables students to produce articles, write letters, express the writer's thoughts, ideas, and observations, whatever the occasion is, in a correct, clear and influential manner, which results in feeling the artistic value of these writings (Al-Busais, 2011).

Writing skill can be dealt according to three aspects: clear calligraphy and its sub-skills, a proper approach to letters of words, and syntax and synergy. Writing includes handwriting, dictation and expressing ideas. writing skill is entrusted with the task of comprehending all the language, whether it is Arabic or other because it affects the writer, through which inventions and ideas come out while the writer contacts his addressees. The truth is that 
language is the tool of communication whether speaking or writing, and students' problems in learning to write are due to arranging and electing words and the composition of meaningful and useful sentences (Omar \& Al Dein, 2018).

Writing skill in Arabic language is defined as registering one's thoughts and spoken voices in written symbols (alphabets) and then ordering them according to the conventions of the language in correct sentences (Al-Jaafra, 2011).

Thus, writing skill is very important and necessary in learning and mastering languages, and it must be focused on and researchers are urged to study it. This study has been similar to Arab and foreign studies in terms of goals, methodology and procedures. This study, together with previous studies, contributed to finding a research base and shedding light on the skill of writing.

\subsection{The Sub-Skills of the Writing Skill}

Writing is an essential element in the educational process; it is like the preserving container for the public and private knowledge, and therefore the concept of writing is related to the branches of Arabic language that are close to each other (Al-Zoukh, 2017):

a. Calligraphy: It is the writing of single Arabic letters, and composites, in a beautiful good manner according to the rules and conventions of the language. Accordingly, the calligraphy is a beautiful writing of the word, sentences or letters according to the rules of the language.

B. Dictation: It is the conversion of understandable audible sounds into written symbols, i.e., into letters that are placed in their correct positions of the word, and the integrity of the word to reach the desired meaning. Dictation is drawing, training for the senses to master, expanding students 'experiences, and testing the learner to write words and know their positions.'

C. Writing Composition: It is the process of expressing feelings, emotions, opinions and needs and converting information into words that are written in correct form, taking into account the rules of grammar, good structure and organization, and the coherence and clarity of ideas.

\subsection{Writing Skill Goals}

The primary goal of teaching writing is to foster students' ability to express themselves by helping them acquire the ability to express ideas, sensations, emotions and feelings in a high and influential manner with broadness and spaciousness of creativity. Moreover, it provides students with the ability to express in a sound language which takes into account the rules of good use of syntactic, morphological, and semantic systems giving them the ability to practice logical thinking in presenting ideas to influence the recipient, and develop students' ability to face different life situations such as writing a greeting card or message to a friend (Khasawneh, 2008). Writing skill has a set of special goals, which are:

1) Cognitive Goals: The learner's ability to write a good composition easily, and the ability to express ideas systematically, and the formation of many mental capabilities such as correct judgment, accurate observation and strong attention.

2) Kinetic Goals: Teaching learners to draw the shapes of letters in a word and get along with one another, strengthen the muscles of the hand, and train learners to listen well to clear, sound writing.

3) Emotional Goals: Instilling moral values among learners, for example: building many artistic abilities such as realizing the beauty and good taste, developing learners' technical talents and encouraging them to be creative (Ta'aima \& Manna, 2011).

\subsection{Research Problem and Questions}

Zaqqout (1999) confirms that despite the importance of composition as the most important goals and objectives of linguistic and literary studies, students have weakness in both oral and written composition in all levels of education - primary, preparatory, and secondary — and this weakness may even reach to university level. Some other studies, such as the study of Madkour (2000), indicate that those who follow the reality of writing, both written and oral, find it neglected in public and private schools. It is performed in a routine manner that has no spirit and no life, and its lessons in the weekly schedule do not exceed one class. Some teachers and educational supervisors are unaware of its teaching methods, skills, and corrections.

The research problem is, according to the researchers' knowledge, that there are no previous studies that have investigated the level of the students' ability in writing skill in Arar's schools. This skill is of the utmost importance as it is not possible for those who do not master it or cannot perform it properly to understand what is 
written, or express their thoughts, or transfer their knowledge. This makes it necessary to approach this area and diagnose its reality, setting and solutions that are expected to improve the students' level in writing skill at this stage in the future. The problem of this research is to identify students' ability level in writing skills in the Arabic language. This research seeks to answer the following questions:

1) How good are the intermediate students at writing in Arabic?

2) Are there any statistically significant differences at the level of significance $(0.05 \geq a)$ in mastering writing skill in Arabic language depending gender variable?

3) Are there any statistically significant differences at the level of significance $(0.05 \geq a)$ in mastering writing skill in Arabic language depending grade variable?

\subsection{The Significance of the Study}

The importance of current research is due to the following:

- Examining the level of middle school students in writing skills.

- Motivating future researchers, and those who are interested in conducting more research in this field.

- Contributing to creating a database that serves decision-makers and those concerned with the development of the education sector in general.

- Drawing attention to the importance of writing skills, and contribute to raising the level of students' achievement and knowledge.

\section{Research Terms}

Writing Skills: These are the skills that students must possess and measure their degree of writing compositions, which include (hamza writing, nunation writing, writing of the introduction, discussion and conclusion, and written composition) that were measured through a test for this purpose (procedural).

Arabic language: Language is defined idiomatically as phonemic symbols that have compatible systems in structures, expressions, and sounds, and are used for social and individual communication.

Its characteristics are summarized in that it has a specific system in arranging its letters and words. It is acquired through learning. It has meaning and connotations that are understood and known by the listener, the speaker, the reader and the writer, and it has independence and characteristics from other languages. It conveys the content of the message through communication, and is considered a social phenomenon characterized by instability.

The Arabic language course is essential and compulsory for all levels of study in public education.

Intermediate stage: It is the middle stage of the education as it is preceded by primary education and followed by secondary education in the Kingdom of Saudi Arabia, and it occupies a period of time extending from twelve years of age to fourteen years of age. Students learn at this stage: Arabic, the Holy Quran, Biography of the Prophet, Mathematics, Science and English.

\section{Hamza in the Arabic language:}

It is a strong sound that comes out of the larynx and is not described by aloud or whispering, and it is a correct letter that accepts the movement and is located at the beginning, middle and end of the word (See Appendix A).

There is a problem with students in differentiating between the hamza Al Wasl and the hamza, so special lessons are devoted to it to be taught in Arabic language books.

\section{Research Limitations}

Human Limits: It includes middle school students-First, Second and Third Intermediate school.

Time Limits: The study was applied in the first semester of the year 2017-2018.

Spatial Limits: The study was applied to students of the Northern Border Region, Arar, KSA.

\section{Review of Related Literature}

The researchers reviewed the studies related to the variables of the study subject, as numerous studies dealt with writing skill, and the following is a review of Arab and foreign studies:

\subsection{First: Arab Studies}

Al-Hamdani (2016) conducted a study that aimed at identifying the effect of using the guided discovery strategy in the acquisition of communication skills subject for the tenth-grade students in Jordan and knowing their impact on improving their creative writing skills. A purposive sample was chosen from Khaled Bin Al-Waleed School for 
Boys: experimental group, which included 38 students studied using the guided discovery strategy, and the control group which was taught by the usual strategy, and it included 42 students. The study tools consisted of an achievement test in the subject of communication skills and the teaching plan prepared according to the guided discovery strategy. The results showed that there were statistically significant differences for the experimental and control groups in the post-test in the achievement test for the communication skills subject in favor of the experimental group. The results also showed that there were no statistically significant differences for the experimental and control groups in the post-test of creative writing skills.

Al-Bayati (2016) conducted a study aimed at identifying the effect of teaching interpretive reading using thinking aloud strategy to improve writing skills for seventh-grade students in Jordan. The sample of the study consisted of 58 students, 27 students in the experimental group, and 31 students in the control group. The most important results of the study were that there were statistically significant differences in favor of the group studied using the thinking aloud strategy. In light of these results, the researcher recommended a set of related recommendations.

Suleiman and Abdel-Rahim (2016) conducted a study that aimed at identifying the difficulties of learning to write for students in the basic stage in Al-Amir Strip in Sudan. The researchers used the descriptive method. The study sample consisted of 120 male and female students from the elementary stage students in Al-Amir Strip in Sudan, and a personal assessment scale for learning difficulty was applied to them. The results showed that there were differences between males and females in the difficulties of learning to write. There are also differences attributed to the educational level of the students' parents of the basic stage. The study concluded with several recommendations, including conducting a survey study to know other difficulties such as the difficulties of learning to read and others.

Al Tamim (2015) aimed at creating a program based on metacognitive strategies to develop persuasive writing skills among high school students. A list of the necessary persuasive writing skills for second secondary students and a test to measure the persuasive writing skills of second secondary students were prepared. A program based on metacognitive strategies was built to develop persuasive writing skills. The study program was applied to a group of second secondary students in Al-Imam Al-Sakhawi Secondary School in the Holy Capital (Makkah Al-Mukarramah), where the researcher used an experimental design and pre- and post-measurements for the same group. The results of the study revealed the following: The effectiveness of the study program in developing persuasive writing skills for second secondary students as a whole, and the effectiveness of the current study program in developing the sub-skills: the general skills for the written subject, writing an introduction for the subject, content writing skills, and finally conclusion writing skills.

Al-Essawi and Aziz'sstudy (2014) aimed to identify the level of using form skills among fifth-grade (scientific stream) students in creative writing. The researcher adopted the descriptive approach, and the study sample consisted of 100 students from schools in Baquba Governorate in Iraq. The research tool included writing on a creative topic. The results showed a decline in creative writing skills_-form skills—among fifth-graders.

\subsection{Second: Foreign Studies}

Vandommele et al.'s study (2017) examined the implications of collaborative, multimedia intervention for writing in two different settings: a task-based in-school intervention and an out-of-school leisure intervention on developing writing skills for beginner learners in the Dutch language as a second language. All participants in both interventions $(\mathrm{N}=52)$ and participants in a non-intervention group $(\mathrm{N}=32)$ completed two writing tasks: (a) producing a folder containing their new hometown information, and (b) writing a story presented to learners in a comic visual mode. The effect of the interventions on developing the L2 writing skills of the participants was evaluated by taking multiple measures in several aspects of writing. Multilevel analyses revealed significantly greater growth for both intervention groups compared to the non-intervention group. The gains were more pronounced in the folder task which was directly related to the intervention in terms of content, compared to the narrative task. As for the control group, a significant decrease in fluency in the folder task was only seen. The in-school group showed growth for six measures (complexity and text length on one task and communicative effectiveness, content, lexical diversity and text length on the other). Also, the out-of-school group revealed greater gains for six measures (complexity on one task and content, two measures of syntactic complexity, lexical diversity and text length on the other). No statistically significant differences were found in the gains between the intervention groups although the in-school learners showed a trend towards greater fluency development in both tasks. Thus, this study showed that indicative activities that include a multimedia composition can foster the development of writing for junior-level II learners, regardless of the precise context in which the activities occur. Moreover, the study shows the importance of using multiple metrics and multiple tasks to assess the development of writing. 
Kim and Schatschneider's study (2017) tackled the direct and indirect effects of component skills on writing (DIEW) using data from 193 children in Grade 1. In this model, working memory was hypothesized to be a foundational cognitive ability for language and cognitive skills as well as transcription skills, which, in turn, contribute to writing. Foundational oral language skills (vocabulary and grammatical knowledge) and higher-order cognitive skills (inference and theory of mind) were hypothesized to be component skills of the next texts (i.e., discourse-level oral language). Results from structural equation modeling largely supported a complete mediation model among 4 variations of the DIEW model. Discourse-level oral language, spelling, and handwriting fluency completely mediated the relations of higher-order cognitive skills, foundational oral language, and working memory to writing. Moreover, language and cognitive skills had both direct and indirect relations to discourse-level oral language. Total effects, including direct and indirect effects, were substantial for discourse-level oral language (.46), working memory (.43), and spelling (.37); followed by vocabulary (.19), handwriting (.17), the theory of mind (.12), inference (.10), and grammatical knowledge (.10). The model explained approximately $67 \%$ of the variance in writing quality. These results indicate that multiple language and cognitive skills make direct and indirect contributions, and it is important to consider both direct and indirect pathways of influences when considering skills that are important to writing.

Kim, Puranik and Otaiba, (2017) conducted a study to identify the growth trajectories of writing in the First Grade and study the effects of SES, language, and/or speech impairment at Florida State University and the Florida Center for Reading Research. The growth trajectories of writing and the relation of children's socioeconomic status, and language and/or speech impairment to the growth trajectories were examined. First-grade children $(N$ $=304$ ) were assessed on their written composition in the fall, winter, and spring, and their vocabulary and literacy skills in the fall. Children's SES harmed writing quality and productivity. Children with language and/or speech impairment had lower scores than typically developing children in the quality and productivity of writing. Even after accounting for their vocabulary and literacy skills, students with language and/or speech impairment had lower scores in the quality and organization of writing. Growth rates in writing were not different as a function of children's SES and language/speech impairment status. Theoretical and practical implications are discussed.

\section{Methodology and Procedures}

\subsection{The Research Methodology}

The descriptive and analytical approach was chosen, as this approach is considered one of the most appropriate approaches for this study as it helped us study the phenomenon and monitor it as it is in reality, and identify all the causes and factors that help the phenomenon to occur - which is the problem of the study. The study problem was identified, through the researchers' sense of the problem in reality, and the information and data related to the study problem were collected, and the two researchers were able to set the hypotheses of the study that were verified by the existence of questions related to the study. Thus, this research used the descriptive analytical approach through reviewing previous research and studies that discussed the variables of the research subject, designing a measure of the extent of students' ability to write in the Arabic language, statistically analyzing data and writing results and recommendations.

\subsection{The Research Population}

The selection of the study population and sample is of a great importance, as they help the researcher to establish his scientific research in an accurate manner. The population of this study are all middle school students: first intermediate, second intermediate and third intermediate in the city of Arar-in the Kingdom of Saudi Arabia and they numbered 1000 male and female students during the academic year 2017-2018.

\subsection{The Research Sample}

The sample must represent the population from which it was taken in order to circulate the results of his research, and therefore the sample of this study was taken amounting to 300 male and female students from the intermediate stage - the first, second and third intermediate - in the Northern Border Region/Arar, and Table 1 shows the distribution of the study sample according to the gender and grade variables. Consents have been obtained concerning the participation of the students, especially female participants. 
Table 1. Distribution of the study sample according to gender and grade variables $(n=300)$

\begin{tabular}{llll}
\hline Class & Gender & Repetition & Percentage \\
\hline The First Intermediate & Male & 50 & 16.66 \\
& Female & 50 & 16.66 \\
& Total & 100 & 33.33 \\
The Second Intermediate & Male & 50 & 16.66 \\
& Female & 50 & 16.66 \\
& Total & 100 & 33.33 \\
The third Intermediate & Male & 50 & 16.66 \\
& Female & 50 & 16.66 \\
Grand Total & Total & 100 & 33.33 \\
& - & 300 & $100 \%$ \\
\hline
\end{tabular}

\subsection{The Search Tool}

The researcher prepared a written mastery test for students. It included measuring five skills: hamzah writing, hamzah marks, nunation writing, cohesion and coherence in writing, and writing composition. The test consisted of five questions, divided into three questions for measuring the skill of spelling (hamzah writing, hamzah mark, and nunation writing), and two questions for measuring cohesion and coherence in writing, and writing composition.

\subsection{The Validity of The Test}

To ensure the validity of the content of the research test, it was presented in its primary form to 8 arbitrators who had experience and competence in the Arabic Language and its teaching methods to judge the degree of integrity and clarity of the language formulation of the test paragraphs, and the extent of their suitability to measure what they were prepared for. In addition, they were asked to suggest any deletion, amendment, or addition to the test items or any suggestions they deem appropriate. The arbitrators' observations and proposals were taken into consideration and the test was modified based on the consensus of the majority of the arbitrators, and the test was finalized. A percentage of $85 \%$ was agreed upon, and this percentage can be relied upon to conduct the study.

To ensure this, the test was applied to a survey sample consisting of 20 male and female students from outside the study sample to calculate the internal consistency of the test by calculating the correlation coefficient of the degree of each dimension with the total score of the test as well as the score of each test item with the total degree of the dimension using Pearson's equation, and Table 2 illustrates this.

Table 2. The correlation coefficient of written skills with the overall score of the test

\begin{tabular}{lll}
\hline Dimensions & Pearson coefficient & Significant value \\
\hline Hamzah Writing & 0.87 & 0.01 \\
Hamzah Mark & 0.81 & 0.01 \\
Nunation Writing & 0.85 & 0.01 \\
Cohesion and coherence in writing & 0.84 & 0.01 \\
Writing Composition & 0.79 & 0.01 \\
\hline
\end{tabular}

\section{The Reliability of the Test}

To ensure the reliability of the writing test, it was applied twice with a two-week time interval on an exploratory sample of 20 male and female students chosen from outside the original sample and from the same research population. The Pearson correlation coefficient of the two tests was calculated to ensure the reliability of repeat, and a stability equation tool (Alpha Cronbach) was applied to the test as a whole. The results showed that the Cronbach Alpha coefficients amounted to 0.85 , as well as the constant stability coefficients 0.87 , which were high and were accepted to apply the research since the stability coefficient is acceptable if it exceeds 0.70 .

\section{The Correction of the Test}

The first question included 10 paragraphs and each correct answer was given 0.5 point, and the second question included 12 paragraphs and each correct answer was given 0.5 point, and the third question included 9 paragraphs and each correct answer was given one point, but the wrong answer was given 0 point. As for the fourth and fifth questions, they included writing on a specific topic, and the answer to each question is given a score ranging from $0-10$ points. Therefore, the total score of the test as a whole range from $0-40$ points. 


\subsection{The Research Variables}

The research variables included:

\section{Independent Variable:}

- Gender: male, female.

- The grade has three levels: (the First Intermediate, the Second Intermediate, and the Third Intermediate).

\section{Dependent Variable:}

- The level of the intermediate school students in Arabic writing.

\subsection{Statistical Processing}

To answer the research questions, the following statistical processes were used through the SPSS Program:

- Cronbach Alpha for ensuring the stability and Pearson correlation coefficient for ensuring the stability of the test research.

- Mean averages and standard deviations for all writing skills and the total score.

- Two Way Analysis of Variance (2-Way ANOVA) to detect differences in the overall score of the test, according to gender and grade variables.

- Sheffie tests to detect the differences according to the grade variable.

\section{Results and Discussion}

The results of the first main question: What is the level of intermediate school students' ability to write in the Arabic language?

To answer this question, mean averages and standard deviations were calculated for each of the writing skills and the total score for the test, and Table 3 shows that.

Table 3. Mean averages and standard deviations for all writing skills and the overall score $(n=300)$

\begin{tabular}{llllll}
\hline No. & Item & Mean average & Standard Deviations & Maximum Score & Percentage number \\
\hline 1 & Hamzah Writing & 2.90 & 0.46 & 5 & $58 \%$ \\
2 & Hamzah mark & 4.56 & 0.72 & 6 & $76 \%$ \\
3 & Nunation writing & 6.38 & 1.00 & 9 & $71 \%$ \\
4 & Cohesion and coherence writing & 8.37 & 1.29 & 10 & $83.7 \%$ \\
5 & Writing composition & 7.98 & 1.25 & 10 & $79.8 \%$ \\
Overall average & 30.19 & 4.71 & 40 & $75.47 \%$ \\
\hline
\end{tabular}

It appears from Table 3 that the percentage of the arithmetic mean for writing skills ranged between $58-83.7 \%$, the most prominent of which was the skill of cohesion and coherence in writing, and the lowest was for the skill or mastery of hamzah writing. The arithmetic mean for the test as a whole was 30.19 of 40 i.e., $75.47 \%$, this indicates a moderate degree of mastery among male and female intermediate school students. This is due to the weakness of the teaching methods and ways used in teaching Arabic language skills in general and writing skills in particular, as the methods and ways of teaching the Arabic language that is adopted by teachers do not depend on activities and practical application of writing skills effectively but depend on indoctrination. The skills of cohesion and coherence in writing came at the highest average due to the great interest in proper spelling methods, the proper drawing of spelling words and dictation skills, the use of appropriate linking words and appropriate punctuation marks, and ensuring that students' writings are free of spelling and grammatical errors. However, hamzah writing ranked last because of common errors among students about methods of writing Hamazah such as medium Hamzah, radical Hamzah, Alef and, conjunctive Hamzahs, and poor teaching methods used to address this weakness. These results were in agreement with the results of the Al-Essawi and Aziz's study (2014), which showed a decrease in writing skills - form skills - among fifth-grade students.

Results of the second and third questions: Are there any statistically significant differences at the level of significance $(0.05 \geq a)$ in mastering writing skill in Arabic language depending gender variable?

3) Are there any statistically significant differences at the level of significance $(0.05 \geq a)$ in mastering writing skill in Arabic language depending grade variable?

To answer these questions, a two-way analysis of variance (2-Way ANOVA) was applied, and Table 4 illustrates 
this.

Table 4. Results of two-way analysis of variance (2-Way ANOVA) to detect differences in the overall score of the test is according to the gender and grade variables $(n=300)$

\begin{tabular}{llllll}
\hline Variable & Sum of squares & Degrees of freedom & mean of squares & value of $\mathrm{F}$ & statistical significance \\
\hline Class & 2001.90 & 2.00 & 1000.95 & 64.84 & 0.00 \\
Gender & 51.21 & 1.00 & 51.21 & 3.32 & 0.07 \\
Error & 4569.47 & 296.00 & 15.44 & & \\
Corrected total & 6622.57 & 299.00 & & & \\
\hline
\end{tabular}

It appears from Table 4:

- There were no statistically significant differences at the level of significance 0.05 according to the gender variable, where the value of $\mathrm{F}$ was 3.32 and the level of significance 0.07 . This is due to the exposure of middle school students in the Northern Border Region schools in Saudi Arabia to the conditions of a converging learning environment. Besides, they receive the same subject matter as well as the similarities among methods of teaching Arabic language teachers. These results differed with the results of Suleiman and Abdul Rahim's study (2016), which showed differences between males and females in the difficulties of learning to write.

- There are statistically significant differences at the level of significance 0.05 according to the grade variable, where the value of $\mathrm{F}$ was 64.84 and statistically significant 0.00 , and to detect the differences (Sheffe) test was applied, and Table 5 illustrates this.

Table 5. Sheffie test results to detect differences according to grade variable

\begin{tabular}{lllll}
\hline Class & SMA & The First Intermediate & The second Intermediate & The third Intermediate \\
\hline The First Intermediate & 26.55 & - & $5.14^{*}$ & $5.78^{*}$ \\
The second Intermediate & 31.69 & - & 0.64 \\
The third Intermediate & 32.33 & & & - \\
\hline
\end{tabular}

It appears from Table 5 that the differences were between the First Intermediate and the Second and Third Intermediate, and in favor of the Second and Third intermediate, with an average of 31.69, 32.33 respectively, while the mean for the First Intermediate grade was 26.55. This is because students of the Second Intermediate and Third Intermediate Grades received better educational experiences in the Arabic language classes than the First Intermediate Grade students, and read an advanced educational course than the First Intermediate Grade students.

\section{Conclusion and Recommendations}

The results showed there were no statistically significant differences in students' ability level in writing skill according to gender variable. The results revealed that there were statistically significant differences in the students' ability level in writing skills according to the grade variable in favor of the third-grade average.

In light of the results of the study, the researchers recommend the following:

1) The necessity of raising teachers' awareness of the Arabic language in developing some writing skills for students, such as writing hamzah and writing nunation.

2) Organizing training courses for teachers to introduce them to effective and modern teaching methods for teaching writing skills to students.

3) Developing remedial plans and programs for some students with weak writing skills, to improve their writing performance.

4) Conducting studies and research on the level of the students' ability to write for other levels of study such as the secondary stage and the university stage.

\section{Acknowledgement}

The authors gratefully acknowledge the support for this research study via grant no.7108-EAR-2017-1-7-F from the Deanship Of Scientific Research at Northern Border University, Arar, Saudi Arabia.

\section{References}

Al Zoukh, B. (2017). The Effectiveness of Language Exercises in Developing Writing Skills for Arabic Language 
Learners in the First Elementary Stage. Unpublished Master Thesis, University of Kassadi Merbah, Algeria.

Al-Bayati, A. (2016). The Effect of Teaching Explanatory Reading Using Thinking Aloud to Improve Written Expression Skills for Seventh- Grade Students in Jordan. Unpublished Master Thesis, University of Al-Bayt, College of Educational Sciences, Jordan.

Al-Busais, H. (2011). The Development of Reading and Writing Skills, Multiple Teaching and Evaluation Strategies. Damascus: Publications of the Syrian General Book Authority.

Al-Hajj, O. (2018). The Application of Linguistic Play "Card Chestgame" in Teaching Arabic to Upgrade Writing Skills. The Journal of Teaching Arabic Language, 10(1), 119-132.

Al-Hamdani, A. (2016). A Program Based on Metacognitive Strategies to Develop Persuasive Writing Skills for High School Students. Master Thesis, College of Educational Sciences, Al Al-Bayt University.

Al-Hogail, S. (1421). Education System and Policy in the Kingdom of Saudi Arabia (4th ed., p. 135). Al-Sharif Press.

Al-Issawi, R., \& Aziz, S. (2014). The Level of Using Form Skills Among Fifth-Grade Students in Creative Writing. Al-Fateh Magazine, 59, 223-244.

Al-Jaafirah, A. (2011). Arabic Language Curricula and Teaching Methods Between Theory and Practice. Amman: Arab Society Library for Publishing and Distribution.

Al-Shanti, M. (2003). Language Skills: An Introduction to the Characteristics of the Arabic Language (5th ed.). Beirut: Al-Andalus House Publishing and Distribution.

Al-Sunbul, A. (1412). The Education System in the Kingdom of Saudi Arabia (p. 20).

Al-Tamim, A. (2015). A Program Based on Metacognitive Strategies to Develop Persuasive Writing Skills for High School Students. Educational Journal, 29(114), 599-663.

Arabic Language. (2019). What is hamza in Arabic? Retrieved from https://www.ibnulyemenarabic.com/arabic-language/hamza-in-arabic/

Kazdin, A. (2000). Encyclopedia of Psychology (Vol. 8). Washington, DC: American psychological association.

Khasawneh, R. (2008). The Foundations of Teaching Creative Writing. Amman: Jadara for the international book.

Kim, Y., Puranik, C., \& Otaiba, S. (2015). Developmental Trajectories of Writing Skills in First Grade: Examining the Effects of Ses and Language and/or Speech Impairments. The Elementary School Journal, 115(4), 593-613. https://doi.org/10.1086/681971

Kim, Y., \& Schatschneider, C. (2017). Expanding the Developmental Models of Writing: A Direct and Indirect Effects Model of Developmental Writing (Diew). Journal of Educational Psychology, 109(1), 35-50. https://doi.org/10.1037/edu0000129

Madkour, A. (2000). The Development of Arabic Language Arts and Its Skills in the Basic Stage. The conference of caring for the Arabic language in the scientific life, League of Arab States.

Suleiman, A., \& Abdel-Rahim, R. (2015). Difficulties in Learning to Write and Its Relationship with Some Variables for the Primary Stage Pupils in the Al Amir Strip in Sudan. Unpublished Master Thesis, University of Khartoum, Sudan.

Taima, R., \& Manna, M. (2011). Teaching Arabic in General Education, "Theories And Experiences". Cairo: Dar Al Fikr.

Vandommele, G., Van den Branden, K., Van Gorp, K., \& De Maeyer, S. (2017). In-School and Out-of-School Multimodal Writing as an L2 Writing Resource for Beginner Learners of Dutch. Journal of Second Language Writing, 1060-3743. https://doi.org/10.1016/j.jslw.2017.05.010

Zaqqout, M. S. (1999). The Guide in Teaching Arabic (2nd ed.). Gaza: Al-Amal Library for Printing, Publishing and Distribution.

\section{Appendix A}

https://www.ibnulyemenarabic.com/arabic-language/hamza-in-arabic/ 
[hamza] is the first letter of the Arabic Alphabet [alif, ba, ta ...], so it is basically the [alif]. However, there are two types of [alif]. As for its position in the word, [hamza] occurs at the beginning, in the middle, or at the end. When it occurs at beginning of the word, it is part of the root word or an addition. Also, it indicates the imperfective المُضضَارع or a yes-no question. As for its shape, it is determined by short vowels [al-Harakaat al-qasiirah].

Types of [alif]:

There are two types of [alif]: the [hamza] and [alif madd]. In Arabic grammar, the [hamza] is the first letter of the alphabet, and it is called the firm [alif], while [alif madd] is the long vowel [ 1 ], and it is called the flaccid [alif].

Being firm, the [hamza] is accompanied by the short vowels [al-Harakaat al-qasiirah]. By the same token, being flaccid the [alif madd] is not accompanied by short vowels; it is always [saakin], that is, it is accompanied by [sukuun].

The [hamza] occurs at the beginning, in the middle, and at the end of words, while [alif madd] occurs in the middle or at the end of words.

The [hamza]

(a) For being firm, the [hamza] is always accompanied by a short vowel: [fatHah], as in (1), (3), (4), and (6) [kasrah], as in (7) and إلَى in (3), or [DHammah], as in (5).

(b) The [hamza] of the definite article آ always has [fatHah] over it.

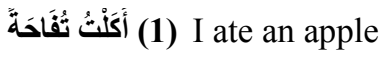

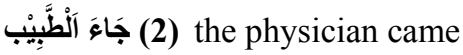
(3) I go to school

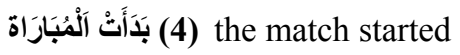
(5) write the lesson!

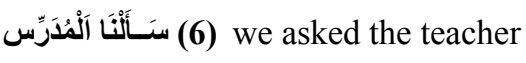
(7) open the door!

The [alif madd]

(a) The [alif] in these words is called [alif madd], also known as [alif layyinah] which literally means 'flaccid'.

(b) Being flaccid, it does not accept a short vowel, so it is always [saakin], i.e., accompanied by [sukuun], as in the examples.

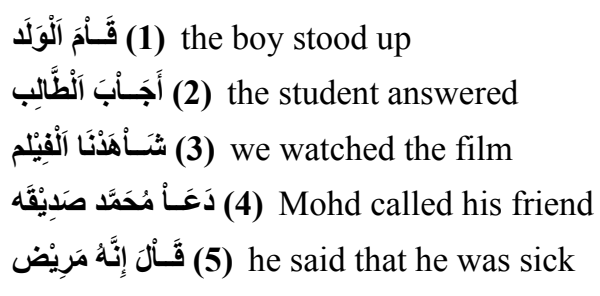

(1) the boy stood up

(2) the student answered

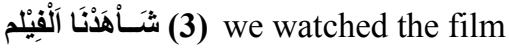

(4) Mohd called his friend

Position of the [hamza]:

Unlike the [alif madd], the [hamza] occurs at the beginning of the word (as I, !, or I), in the middle of the word

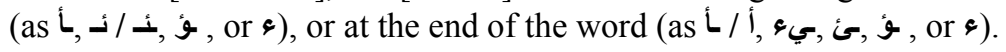

(a) In these examples, the [hamza] occurs at the beginning of the word.

(b) In (1) and (2), it is part of perfective root verb.

(c) It occurs at the beginning $2^{\text {nd }}$ person pronouns and the $1^{\text {st }}$ person singular, as in (3) and (4).

(d) In (5) and (6), it indicates the imperfective form the verb referring to the first person singular.

(e) It is used at the beginning of the imperative verbs. Here it is [hamzat al-wasl].

(f) It is also used at the beginning of some nouns and particles, as in (9) and (10).
(1) Ali closed the door

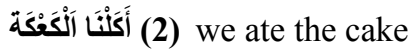

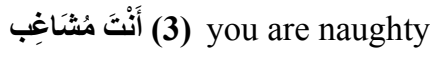

(4) I am sleepy

(5) I أُرِيْدُ عَصِيْرًا

(6) I know the answer

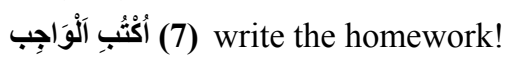

(8) listen to me!

(9) my sister is a writer

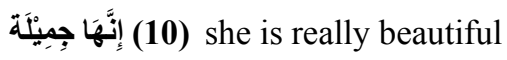


(a) In these examples, it occurs in the middle of the word.

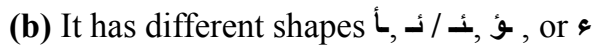

(c) Its shape is determined by the short vowel over it or over the letter that precedes it, as explained below.

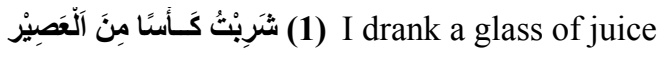

هُ مُ (2) is hungry

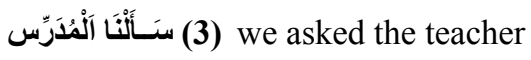

في (4) this is painful

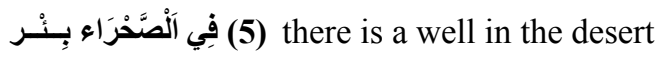

(6) this is the reading book

(a) In these examples, it occurs at the end of the word.

(b) In this position, it has different shapes. The shape is determined by the shorts over the preceding letters, as explained below.
(1) the minister came
(2) the race started
(3) you are slow

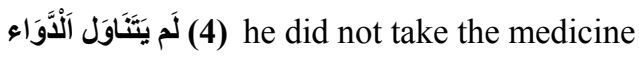
(5) we went to the desert

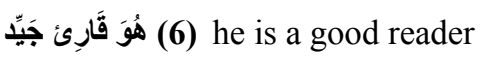

[hamza] and Yes-no Question:

[hamza], namely I with fatHah over it, is used to ask a yes-no question in Arabic. It is used in the same way as a

The only difference between the two is that questions with [hamza] are formal.
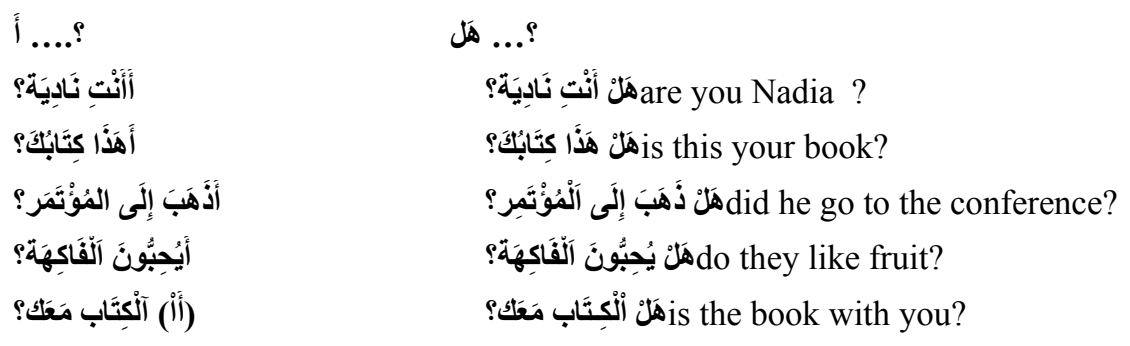

The Shape of the [hamza]:

At the Beginning of the Word:

(a) If the [hamza] (\&) has [fatHa] or [DHammah] over it, it always placed over the [alif], as in (1) and (3).

(b) If the [hamza] (\&) has [kasrah] below it, it is written below the [alif], as in (2).

In the Middle of the Word:

(a) If the letter before the [hamza] has [fatHah] over it, the [hamza] is placed over the [alif], as in (1).

(b) If the letter before has [kasrah] below it, the [hamza] is placed on the line $\dot{-}$, as in (2).

(c) If the letter before has [DHammah] over it, the [hamza] is placed on 9 , i.e. $f$, as in (3).

(d) If the letter before it has [sukuun] over it, the [hamza] is written on the line by itself $\varepsilon$, as in (4).

At the End of the Word:

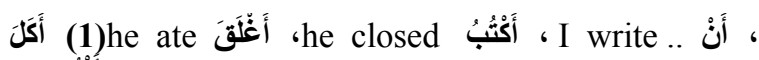

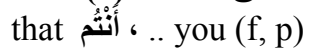

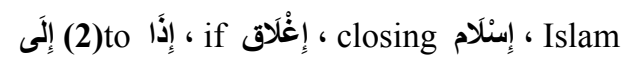

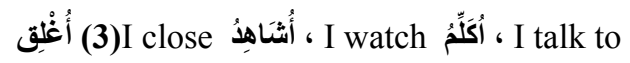

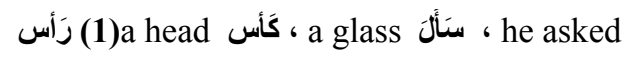

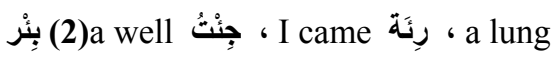

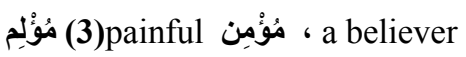

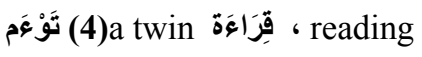


(a) If the letter before the [hamza] has [fatHah] over it, the [hamza] is placed over the [alif], as in (1).

(b) If the letter before it has [sukuun] over it the [hamza] is placed by itself on the line, as in (2).

(c) If the letter before it has [DHammah] over it, the [hamza] is placed on 9 , i.e. 'f, as in (3).

(d) If the letter before it has [kasrah] below it, the [hamza] is written on $、$, i.e. [yaa'] without the two dots below it, as in (4).

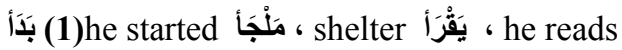

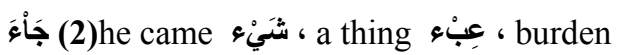

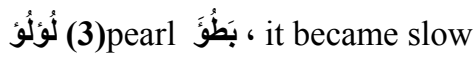

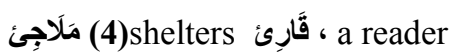

Note: there are other rules for writing the [hamza], but these are the most common.

At the Beginning of the Word:

(a) If the [hamza] (s) has [fatHa] or [DHammah] over it, it always placed over the [alif], as in (1) and (3).

(b) If the [hamza] (\&) has [kasrah] below it, it is written below the [alif], as in (2).

In the Middle of the Word:

(a) If the letter before the [hamza] has [fatHah] over it, the [hamza] is placed over the [alif], as in (1).

(b) If the letter before has [kasrah] below it, the [hamza] is placed on the line $\mathcal{\perp}$, as in (2).

(c) If the letter before has [DHammah] over it, the [hamza] is placed on 9 , i.e. 9 , as in (3).

(d) If the letter before it has [sukuun] over it, the [hamza] is written on the line by itself $\varepsilon$, as in (4).

At the End of the Word:

(a) If the letter before the [hamza] has [fatHah] over it, the [hamza] is placed over the [alif], as in (1).

(b) If the letter before it has [sukuun] over it the [hamza] is placed by itself on the line, as in (2).

(c) If the letter before it has [DHammah] over it, the [hamza] is placed on g, i.e. $q$, as in (3).

(d) If the letter before it has [kasrah] below it, the [hamza] is written on $s$, i.e. [yaa'] without the two dots below it, as in (4).

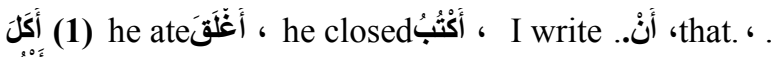
أَنْتُ

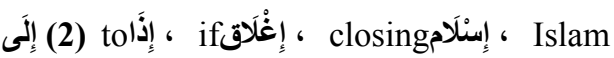

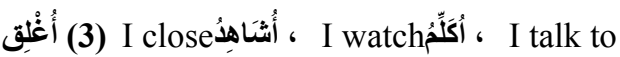

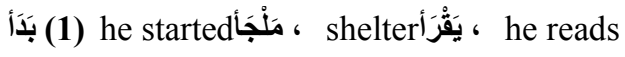

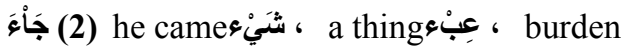

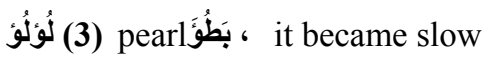

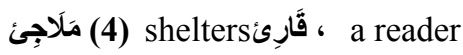

Note: there are other rules for writing the [hamza], but these are the most common.

Two Types of [hamza]:

From the above explanation and from the previous lesson, you can see that there are two types of [hamza]: [alif al-wasl] or [hamzat al-wasl] and [alif al-qaT'] or [hamzat al-qaT'], which means 'disjunctive alif'. Both refer to the [alif] at the beginning of words.

[alif al-qaT'] is the [alif] that has [hamza] (\&) over or below it, while [alif al-wasl] is not accompanied by [hamza]. 
While [alif al-wasl] is only pronounced at the start of sentences, [alif al-qaT'] is always pronounced even if the word in which it occurs is in the middle of the sentence. For this reason, it is called 'disjunctive', that is, it disallows blending / linking with the preceding word.

\section{Appendix B}

\section{Samples of students' writings}

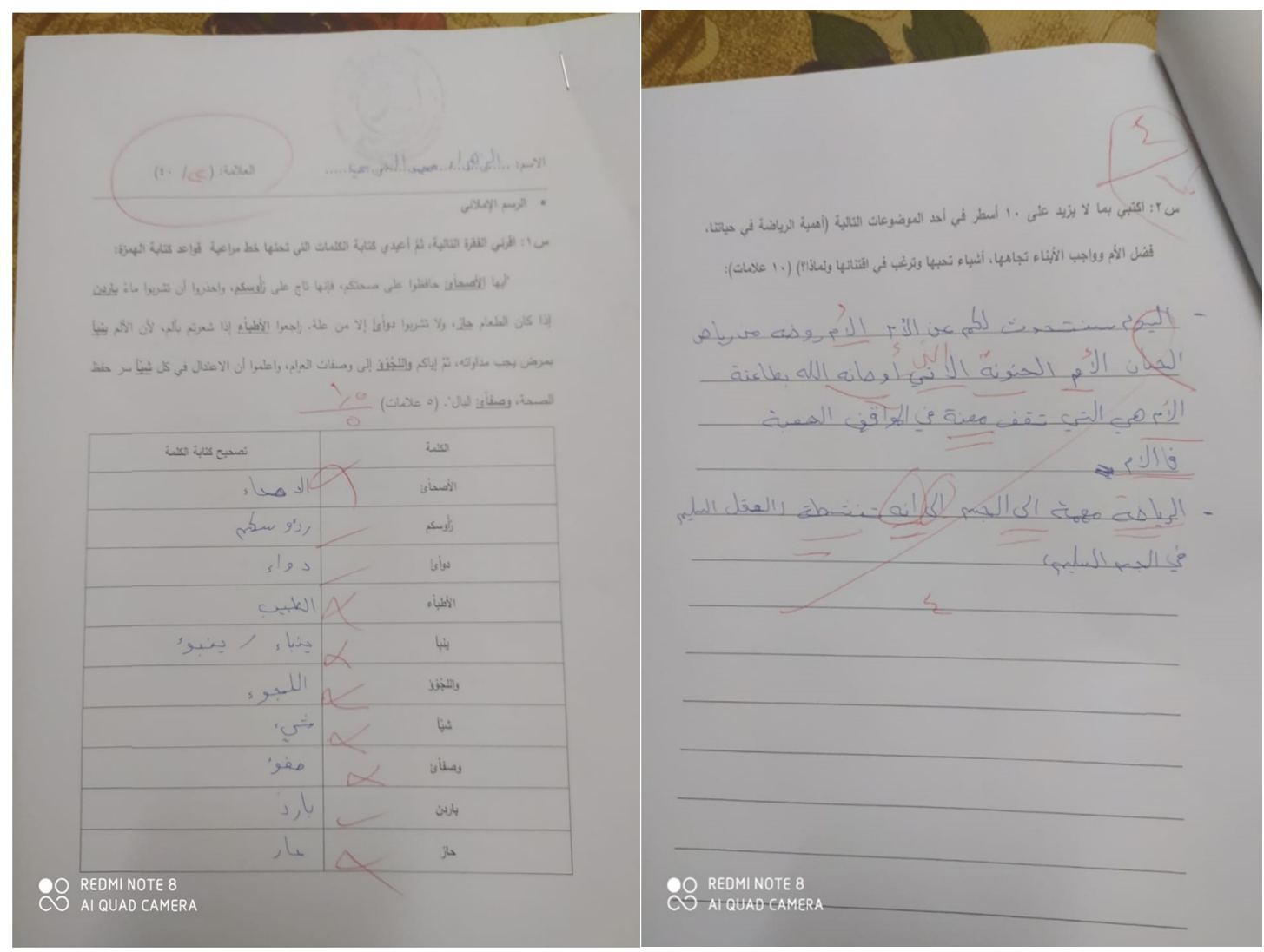




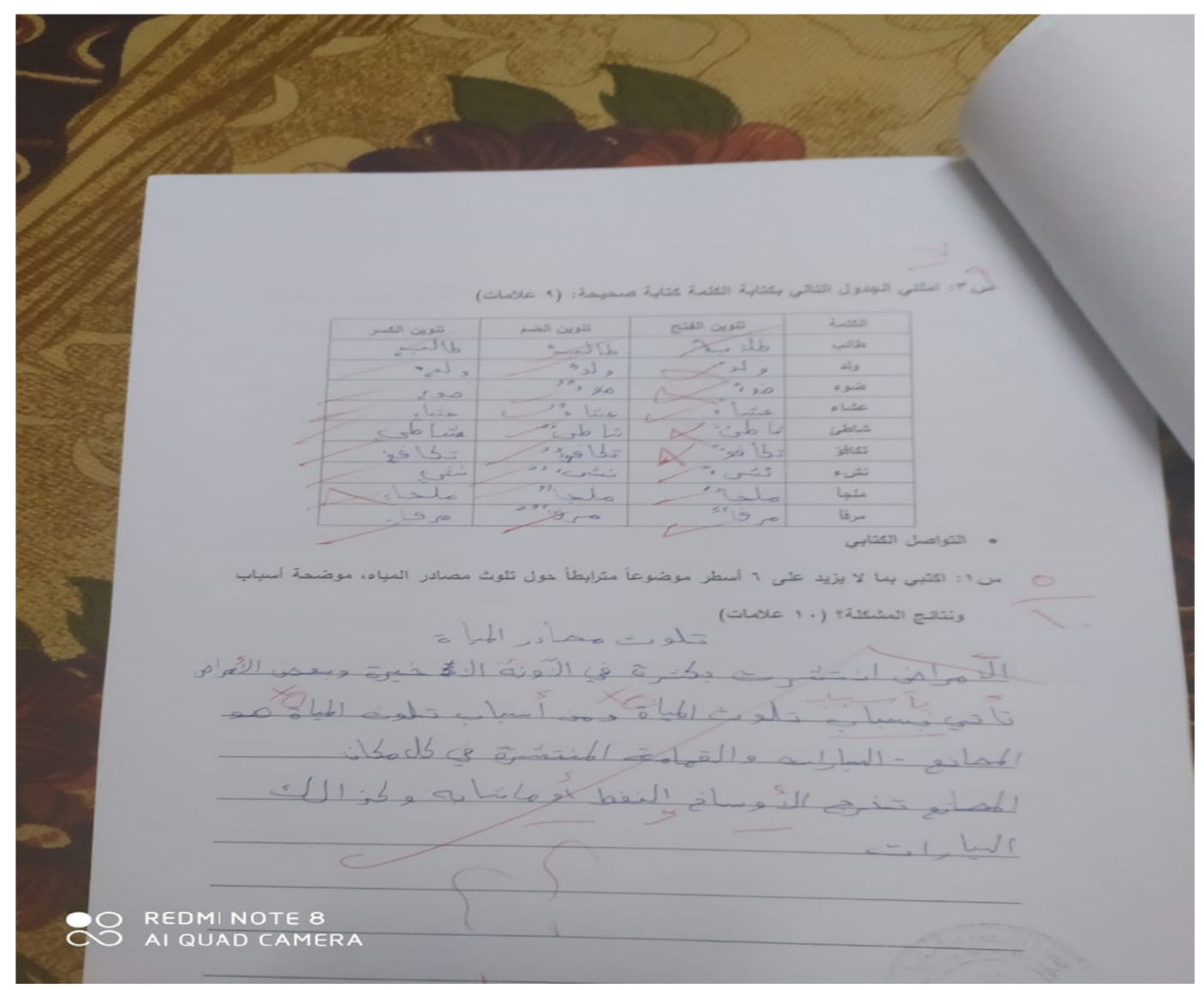




\section{Appendix C}

Documents (consents)

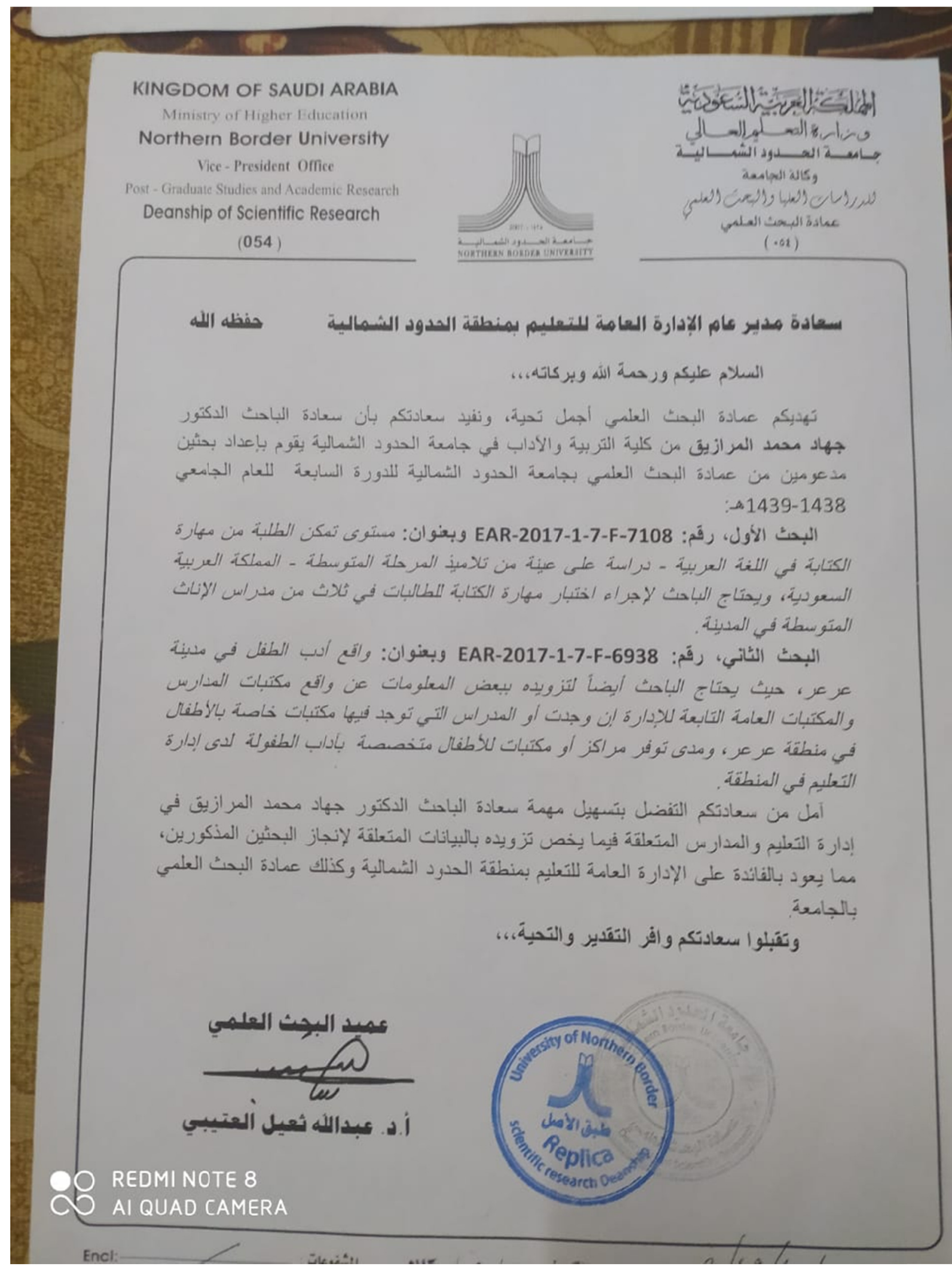




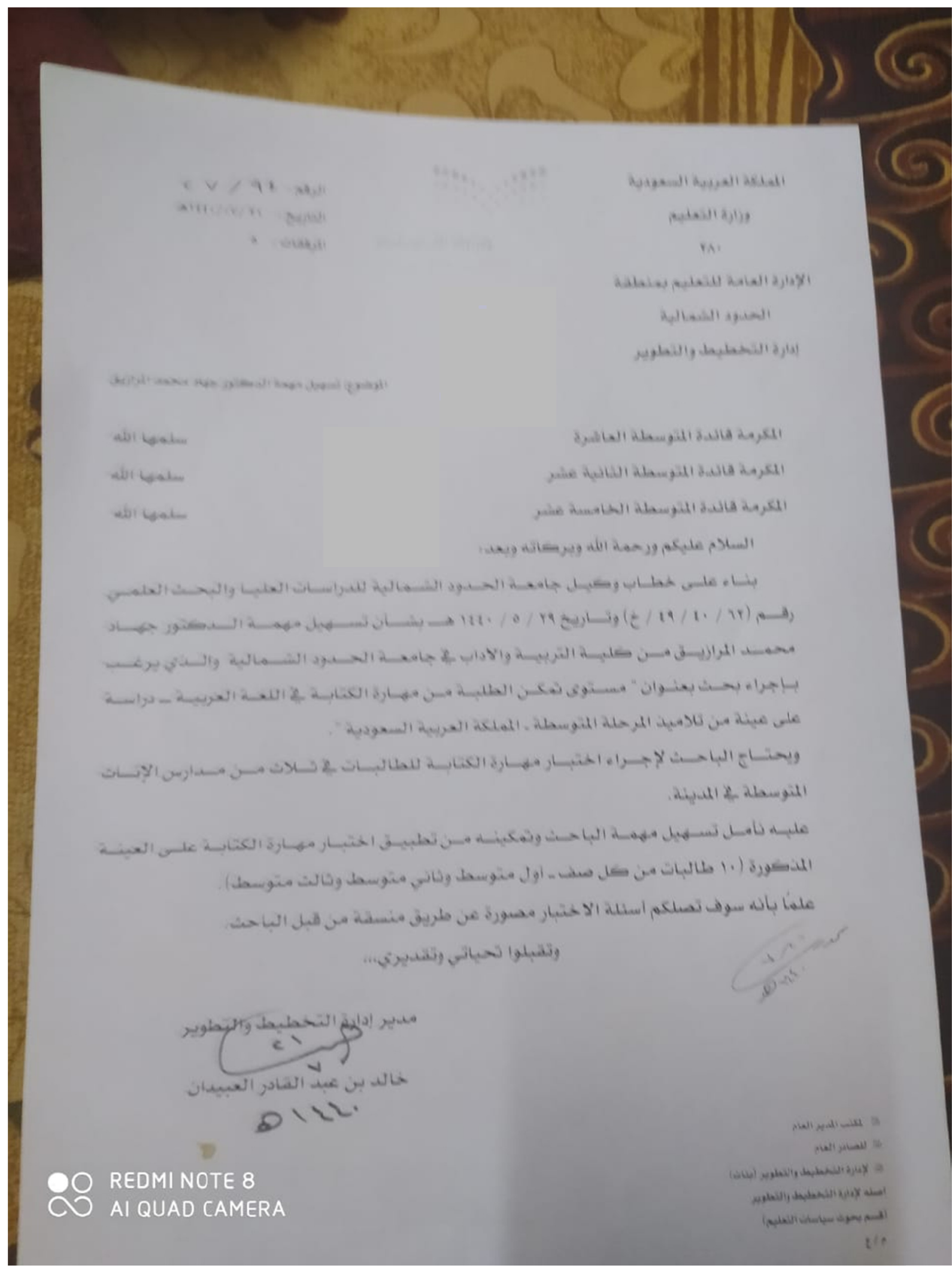




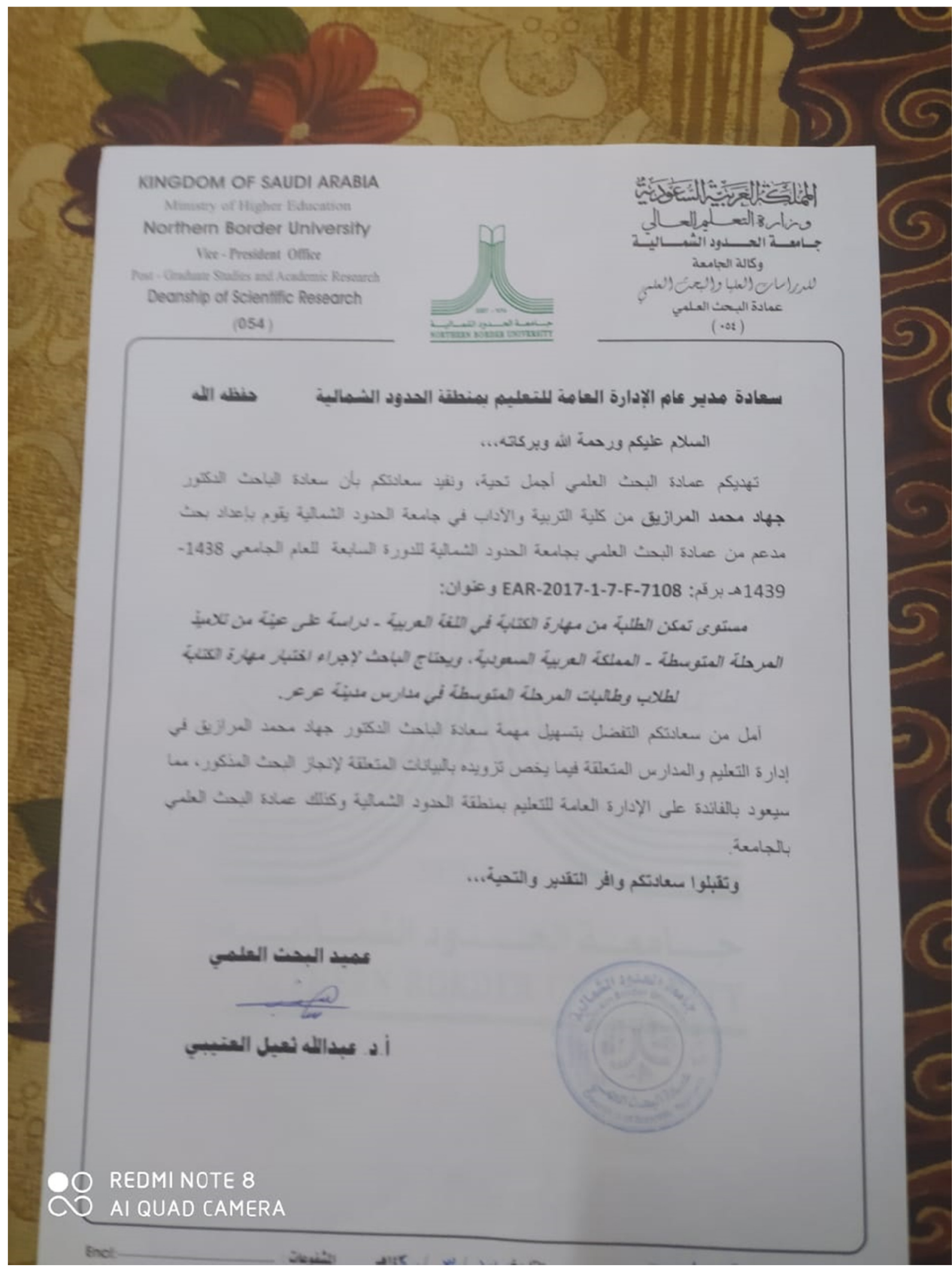

\section{Copyrights}

Copyright for this article is retained by the author, with first publication rights granted to the journal.

This is an open-access article distributed under the terms and conditions of the Creative Commons Attribution license (http://creativecommons.org/licenses/by/4.0/). 